\title{
Physicochemical Properties of Indoor Particulate Matter Collected on Subway Platforms in Japan
}

\author{
Chang-Jin Ma*, Sigeo Matuyama ${ }^{1)}$, Koichiro Sera ${ }^{2)}$ and Shin-Do Kim ${ }^{3)}$ \\ Department of Environmental Science, Fukuoka Women's University, Fukuoka 813-8529, Japan \\ ${ }^{1)}$ Department of Quantum Science and Energy Engineering, Tohoku University, Sendai 980-8579, Japan \\ ${ }^{2)}$ Cyclotron Research Center, Iwate Medical University, Iwate 020-0173, Japan \\ ${ }^{3)}$ School of Environmental Engineering, University of Seoul, Seoul 130-743, Korea
}

*Corresponding author. Tel: +81-92-661-2411, E-mail: ma@fwu.ac.jp

\begin{abstract}
This study was aimed to thoroughly estimate the characteristics of indoor particulate matter (PM) collected on subway platforms by the cooperative approach of semi-bulk and single particle analyses. The size-resolved PM and its number concentration were measured on the platform in a heavily traveled subway station in Fukuoka, Japan. Particle Induced Xray Emission (PIXE) and micro-PIXE techniques were applied to the chemical analyses of semi-bulk and single particle, respectively. There was the close resemblance of timely fluctuation between PM number concentration and train service on the third basement floor (B3F) platform compared to the second basement floor (B2F) and its maximum level was marked in rush hour. Higher number counts in large particles $(>1 \mu \mathrm{m})$ and lower number counts in fine particles $(<1 \mu \mathrm{m})$ were shown on the platform compared to an above ground. PM2.5 accounted for $58.2 \%$ and 38.2 $\%$ of TSP on B3F and on B2F, respectively. The elements that were ranked at high concentration in sizeresolved semi-bulk PM were $\mathrm{Fe}, \mathrm{Si}, \mathrm{Ca}, \mathrm{S}$, and $\mathrm{Na}$. The major elements tending to have more elevated levels on B3F than B2F were $\mathrm{Fe}$ (4.4 times), $\mathrm{Ca}$ (17.3 times), and $\mathrm{Si}$ (46.4 times). Although concentrations were very low, $\mathrm{Cr}\left(11.9 \mathrm{ng} \mathrm{m}^{-3}\right.$ on $\mathrm{B} 3 \mathrm{~F}, 2.4 \mathrm{ng} \mathrm{m}^{-3}$ on $\mathrm{B} 2 \mathrm{~F}), \mathrm{Mn}\left(3.4 \mathrm{ng} \mathrm{m}^{-3}\right.$ on B3F, $0.9 \mathrm{ng} \mathrm{m}^{-3}$ on B2F), and $\mathrm{Pb}\left(0.6 \mathrm{ng} \mathrm{m}^{-3}\right.$ on $\mathrm{B} 3 \mathrm{~F}, 1.6 \mathrm{ng} \mathrm{m}^{-3}$ on B2F) were detected from PM2.5. Individual PM was nearly all enriched in $\mathrm{Fe}$ with $\mathrm{Si}$ and $\mathrm{Ca}$. Classifying and source profiling of the individual particles by elemental maps and particle morphology were tried and particles were presumably divided into four groups (i.e., train/rail friction, train-rail sparking, ballast/abrasive, and cement).
\end{abstract}

Key words: Subway, Indoor, Particulate matter, Individual particle, PM2.5, PM10, Element, PIXE

\section{INTRODUCTION}

Subway is one of the major transportations in most metropolitan areas worldwide. Moreover, by only allowing people to enter and exit the transit network at limited numbers of places, subways tend to mark centers of activity in the city. Hence, this subway system represents a major source of exposure to underground air pollution for millions of people daily. The underground spaces of a subway system (shopping mall, station office, and platform) are also the confined place that may promote the concentration of pollutants both from the outside atmosphere and generated internally. Moreover, gas-phase pollutants such as volatile organic compounds (VOCs) and nitrogen dioxide $\left(\mathrm{NO}_{2}\right)$ emitted from automobile can flow into subway station through ventilating openings or stairs (Son et al., 2011). Therefore, especially for the workers who spend their whole shift below ground, the air quality of the underground spaces of a subway has long been a concern.

Very fine PM can be generated by a high-temperature process when train is breaking. Relatively coarse particles such as splinters are most likely generated by mechanical abrasion (Lorenzo et al., 2006). The fine PM, particularly smaller than $2.5 \mu \mathrm{m}$ in aerodynamic diameter (PM2.5), may cause the largest damage to the respiratory system because of their deposition in the respiratory tract including lung and their ability to remain airborne for long periods. The health effects of PM2.5 have been extensively documented in the past (McDonnell et al., 2000; Pope et al., 1999; Dockery et al., 1993). Small size PM floats in air for a long time in semi-closed spaces such as an underground subway space. Fine PM also contains more carcinogens, mutagens, and environmentally disruptive chemicals than larger particles suspended in air (Pope et al., 1995; Gulyas and Gercken, 1988).

To know the physicochemical peculiarity of PM collected on a subway platform is an essential prerequi- 
site for understanding the indoor air quality of subway. The measured data at subway environment can also provide important information relevant to evaluating the potential for health effects from exposures to airborne PM as well as the effective ventilation systems.

PM collected at subway system has only been addressed in a few studies in Japan (Mori et al., 2007; Furuya et al., 2001; Okinaga et al., 2000; Yoshizawa, 1983; Ozao, 1977). Furuya et al. (2001) carried out their study to accumulate fundamental data on the indoor environments in subway such as the mass concentration, particle size distribution, and elemental constitution of suspended particulate matter (SPM). A similar study in the air in subways and corresponding above-ground areas was performed by Okinaga et al. (2000). However, these fundamental measured data are not enough to provide the full configuration of particle property. To understand more about subway PM, it is important to estimate the relationship between train running and PM generation as well as the distribution and trace components in the size-resolved PM. Moreover, in some cases, the chemical mixing sate of PM derived by single particle analysis can be further utilized for the assessment of its source inventory.

In this study, in order to provide some insights into PM measured in the underground spaces of subway, the combined application of semi-bulk and single particle analyses was undertaken in one of heavily traveled subway stations in Fukuoka, Japan.

\section{EXPERIMENTAL METHODS}

\subsection{Description of Field Study Site}

In this study, N-K subway station, which is one of Fukuoka City Subway stations in Japan, was the target of field measurement. This station was opened in 1982 and has 10,837 passengers per day. Fukuoka is located in the northwest part of Fukuoka Prefecture. This city is the Kyushu's largest and one of the Japan's ten most populated cities. It has three subway lines: the Hako- zaki Line, the Kuko (Airport) Line, and the Nanakuma Line. The Kuko Line runs east-west from Fukuoka Airport to Meinohama via Hakata Station and Tenjin. The Hakozaki Line runs roughly north-south from Kaizuka to Nakasu-kawabata. The N-K subway station is a busy railway junction on the Hakozaki Line and Kūkō Line and can be accessible by underground passage (see Fig. 1). In this N-K subway station, two ventilation systems are operating and their ventilating capacity is $15000 \mathrm{~m}^{3} \mathrm{~h}^{-1}$. Although platform's screen doors were installed at N-K subway station, its height is about $1.4 \mathrm{~m}$ (see Fig. 1). It therefore does not effectively operate to improve the efficiency of station airconditioning systems and to prevent the gush of wind that usually accompanies the approach of trains into stations. The forced type tunnel ventilation fans blow fresh air through the duct that runs down the shaft and into the tunnel. This subway station is also equipped with PM control equipments systems. Train-break pads and linings materials are composed of non-asbestos and lead materials. The rail sleeper and track ballast in the tunnel of station were made of concrete, however the track ballast of some courses of outdoor route was made up of feldspar and granite. Smoking was already prohibited in public spaces including indoor subway station.

The outdoor surroundings of this substation are residential and commercial areas with several point sources such as the Hakata International Port and the Fukuoka Airport (Domestic and International). Four to eightlane roads, with usually moderate traffic, are located $0.2 \mathrm{~km}$ inner of N-K station. The SPM $(\leq 10 \mu \mathrm{m})$ concentration measured in the ambient atmosphere near subway station was around $35 \mu \mathrm{g} \mathrm{m}^{-3}$ (Fujikawa et al., 2008).

\section{2 Particle Collection and Monitoring}

PM sampling and monitoring were performed simultaneously on both B2F and B3F of N-K station (see Fig. 1) from 8:00 AM to 2:00 PM on May 8th, 2006. For the sampling of size-resolved PM, a three-stage

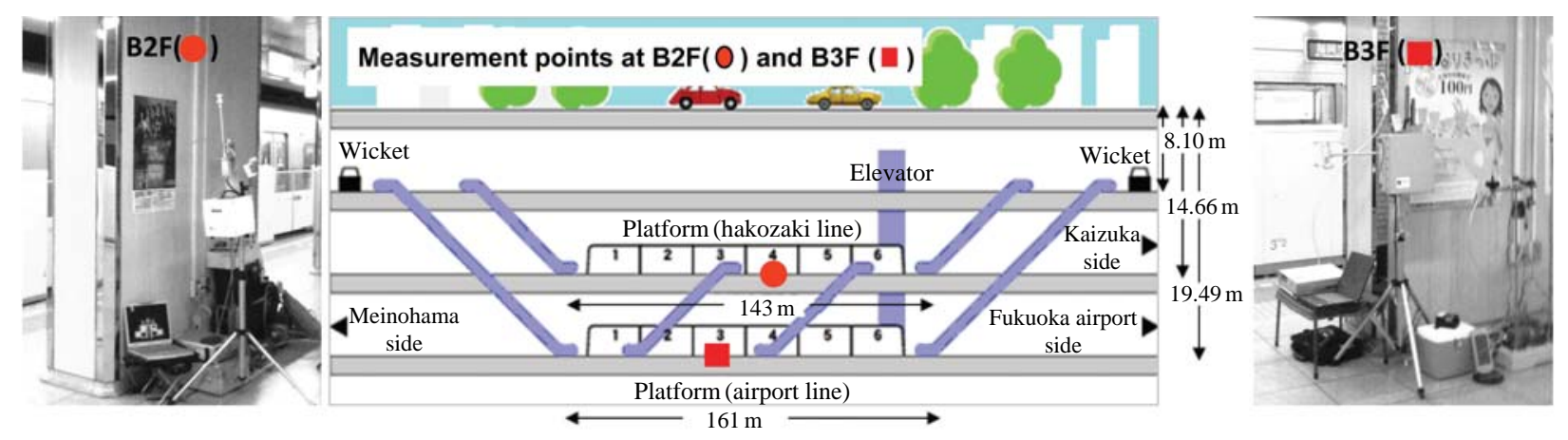

Fig. 1. Cross section view of the N-K station and measuring instruments installed at B2F (left) and B3F (right). 
multi nozzle cascade impactor (MCI) (Tokyo Dylec Co.) was operated. As one of multi-stage PM sampling instruments, this MCI combined with the 1st and 2nd stages having 12-orifice and back-up stage was employed to measure the levels of size-classified mass and the elemental concentrations of PM. Particles were sampled directly on the substrate material arranged behind the jet-nozzles of a cascade impactor. For the collection of particle samples, airflow was maintained at approximately $20 \mathrm{~L} \mathrm{~min}^{-1}$. The size cut-offs PM and filter kind at each stage are giant fraction $(>$ PM10) at the first stage (a $47 \mathrm{~mm}$ diameter, non hole Nuclepore ${ }^{\circledR}$ polycarbonate filter), coarse fraction (PM10-2.5) at the second stage (a $47 \mathrm{~mm}$ diameter, non hole Nuclepore ${ }^{\circledR}$ polycarbonate filter), and fine fraction (PM2.5) at a back-up stage (a $47 \mathrm{~mm}$ diameter, $0.01 \mu \mathrm{m}$ hole Nuclepore $^{\circledR}$ polycarbonate filter), respectively. In order to avoid the direct influence of the stirring up of PM by passengers' steps and to consider the effect of human health, every measurement instrument was installed at $1.6 \mathrm{~m}$ above platform (see Fig. 1). The number concentration of size-segregated PM was also monitored by an optical particle counter (OPC) (RION, KC-01D). Along with these primary measurements, OPC was also operated at the above ground of $\mathrm{N}-\mathrm{K}$ station and two indoor homes that would be expected to have different particle distribution in comparison with underground subway station.

In order to assess a highly time resolved PM2.5 mass concentration, a Dust scan Scout (Rupprecht \& Patashnick Co. Model 3020) was simultaneously operated on B3F. This Dust scan Scout was also worked at the outdoor of N-K station and two general homes in Fukuoka Prefecture. This PM2.5 monitoring system makes use of a near-forward light scattering to assess the concentration of particulate matter in ambient air. The light source is a safety-interlocked laser that operates at a wave length of $670 \mathrm{~nm}$. The scattered light caused by the presence of particles is received by a sensor, forming the basis of the monitor's computations.

\section{3 Elemental Analysis of PM}

\section{3. 1 Semi-bulk PM Analysis}

In order to clearly distinguish the chemical properties and source profiles of small PM from those of large $\mathrm{PM}$, giant fraction ( $>$ PM10) PM and fine fraction (PM2.5) PM collected at the first stage and at backup stage, respectively, were the target of semi-bulk analysis using PIXE. One of PM spots formed behind the jet-nozzles of the MCI cascade impactor was irradiated by the proton beam of PIXE.

In this study, the elemental concentration of semibulk PM was determined by PIXE installed at the Cyclotron Research Center of Iwate Medical University.
This PIXE analytical system has the great advantages such as an excellent sensitivity, a nondestructive technique for multielement with a wide range of elements $(\mathrm{Z}>10)$, and a short measuring time (3-10 minutes for typical environmental samples). The sensitivity, if defined by the ratio of (PIXE yield per unit dose)/(mass thickness), can be determined experimentally and theoretically for all objective elements. For instance, the sensitivity of calcium was calculated to be 1700 (counts $\cdot \mathrm{cm}^{2} / \mu \mathrm{C} \cdot \mu \mathrm{g}$ ) with a detection limit of 9.4 $\times 10^{-3}\left(\mu \mathrm{g} / \mathrm{cm}^{2}\right)$. The more detailed analytical procedures and experimental set-up used for PIXE analytical system were described elsewhere (Sera et al., 1999).

\subsubsection{Single Particle Analysis}

A long sampling duration time causes file up of particles. This file up obscures the chemical determination of particle-to-particle variations. Since particles passing the nozzles of MCI sampler formed a spot on filer, the single particle analysis of current study was restricted to individual particles deposited at the edge of the spot.

In the current study, individual particles were irradiated by the $2.6 \mathrm{MeV}$ proton micro-beam of microPIXE system installed at Department of Quantum Science and Energy Engineering, Tohoku University (Ishii et al., 2001). This micro-PIXE analytical system consists of a dedicated beam line with a doublet quadrupole and a slit-system of micro-slits, divergence-defining slits and baffle slits connected to the 4.5 MV Dynamitron accelerator's energy analyzing system, which was a newly installed second analyzing magnet. The demagnification factors are 8.0 and 27.5 for horizontal and vertical planes, respectively. Performance of the microbeam system was tested by beam scanning across the surface of a copper mesh sample (1000 lines/inch) and measuring the X-ray spectrum. Two X-ray detectors are set in vacuum at 125 degree with respect to the beam axis. The first one has large sensitive area $\left(80 \mathrm{~mm}^{2}\right)$ and is suitable for trace elemental analysis. The second detector has a high-energy resolution ( 136 $\mathrm{eV})$ and a thin Be entrance window $(7.5 \mu \mathrm{m})$ is used to detect low energy X-rays. The two-detector system enables to detect X-rays ranging from $1 \mathrm{keV}$ to $30 \mathrm{keV}$ with sufficient energy resolution. The more detailed analytical procedures, the experimental set-ups, and the QA/QC of micro-PIXE analysis were described elsewhere (Matsuyama et al., 2003; Ishii et al., 2001; IAEA-TECDOC-1190, 2000).

\section{RESULTS AND DISCUSSION}

\subsection{Physical Properties of Subway PM}

Fig. 2 shows the temporal variations of size-resolved particle number concentration and train running num- 


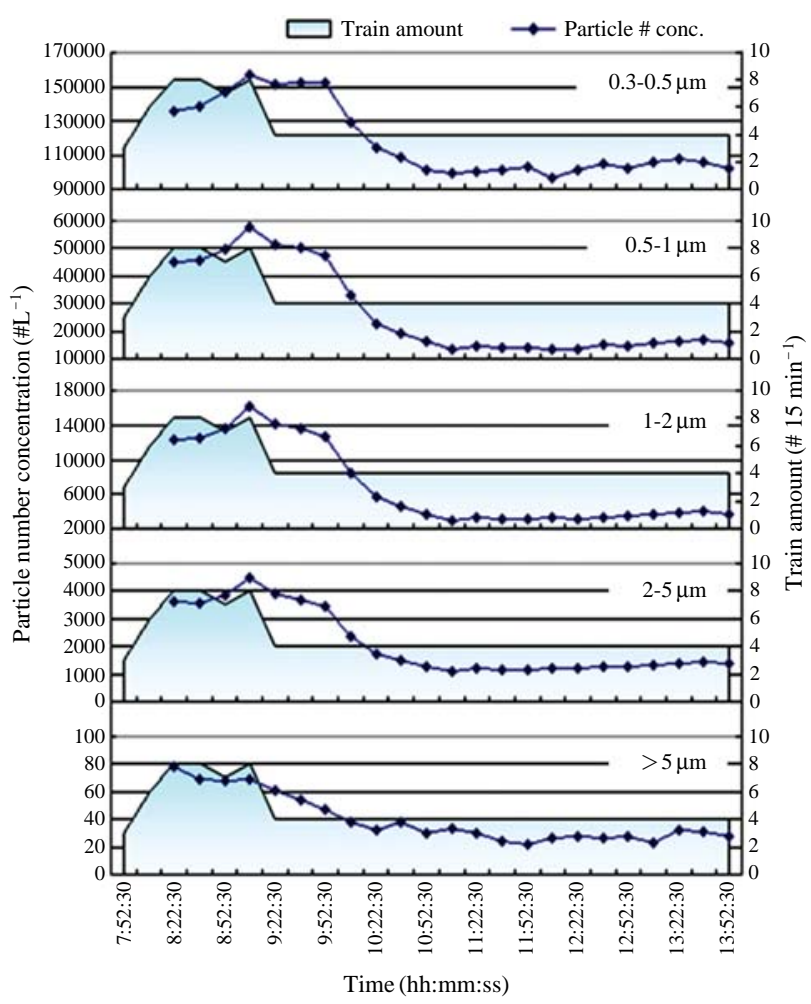

(a)

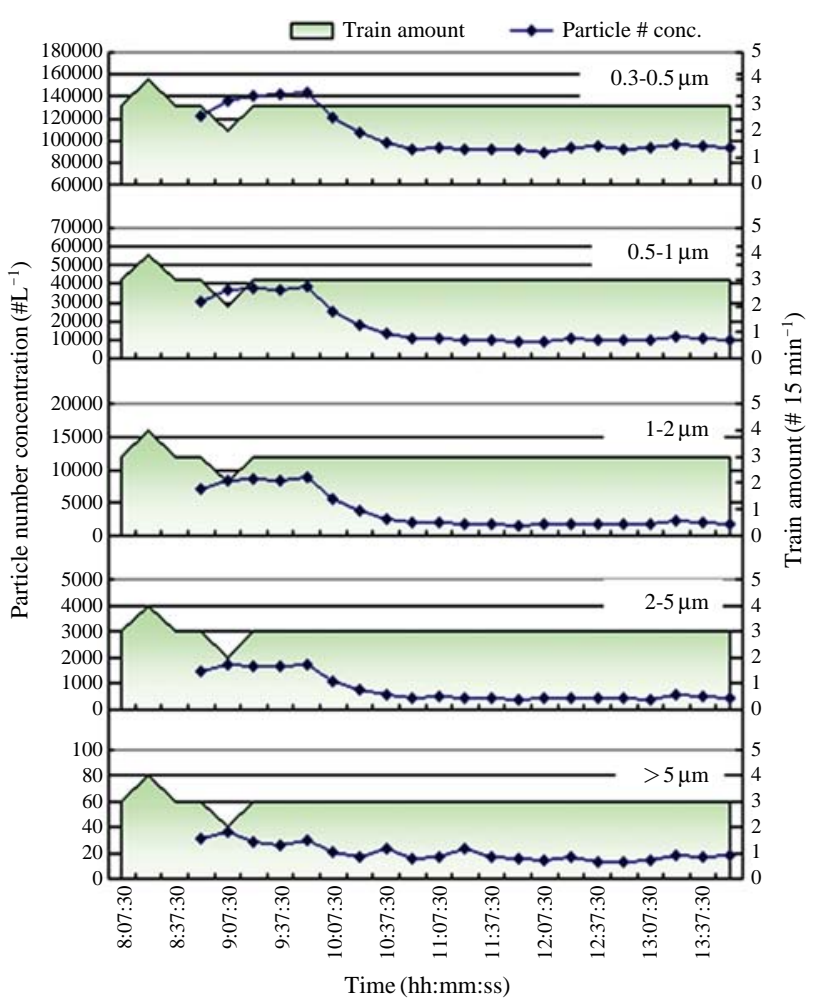

(b)

Fig. 2. Temporal variations of size-resolved particle number concentration and the number of train running at $\mathrm{B} 3 \mathrm{~F}(\mathrm{a})$ and $\mathrm{B} 2 \mathrm{~F}(\mathrm{~b})$.

ber on $\mathrm{B} 3 \mathrm{~F}$ (a) and $\mathrm{B} 2 \mathrm{~F}(\mathrm{~b})$ measured from morning rush hour to afternoon. The number concentration of PM was varied according to the number of train running. As might be expected, the maximum level of PM number concentration was marked in the rush hour period from 08:22 AM to 09:52 AM. And then, the number of PM varied slightly with relatively low level till afternoon. This time series fluctuation of PM number was shown at all particle sizes. However, this phenomenon of $\mathrm{B} 2 \mathrm{~F}$ was relatively insignificant compared to B3F. In order to clearly survey the relevance between PM number concentration and train movement, the size-classified particle number concentration measured while trains run at a constant number (16 trains per hour on B3F, 12 trains per hour on B2F) period (12:29-13:16) was described in Fig. 3. Since all peaks of PM number alteration were formed at the departure time of train on B3F, it can be said that there was strong relationship between the variation of $\mathrm{PM}$ number and train motion. On the other hand, PM number on B2F was not strictly linked with train operation. The reason of this weak interrelation on B2F might be that there were more potential factors for contribution to PM number such as the PM released from shopping mall of $\mathrm{B} 1 \mathrm{~F}$ and the infiltrated outdoor $\mathrm{PM}$ on $\mathrm{B} 2 \mathrm{~F}$ where depth is relatively shallow compared to B3F. In any case, the marked and particular variations of PM number concentration measured on platform of subway shown Figs. 2 and 3 indicate that PM number was greatly influenced by train running. The average particle number concentration on $\mathrm{B} 3 \mathrm{~F}$ varied $10-40 \mathrm{~L}^{-1}$, 7000-1800 L $\mathrm{L}^{-1}, 2000-5000 \mathrm{~L}^{-1}, 10000-23000 \mathrm{~L}^{-1}$, and 95000-115000 $\mathrm{L}^{-1}$ at the aerodynamic particle size of $>5 \mu \mathrm{m}, 2-5 \mu \mathrm{m}, 1-2 \mu \mathrm{m}, 0.5-1 \mu \mathrm{m}, 0.3-0.5 \mu \mathrm{m}$, respectively. This number concentration variation was periodically appeared depending on trains running, namely, there was an elevated and fallen off number concentration at train staying and train pulling off, respectively. The decreasing rates of PM number after train leaving were $75 \%, 61 \%, 60 \%, 56 \%$, and $17 \%$ at the aerodynamic particle size of $>5 \mu \mathrm{m}, 2-5 \mu \mathrm{m}, 1-2 \mu \mathrm{m}$, $0.5-1 \mu \mathrm{m}, 0.3-0.5 \mu \mathrm{m}$, respectively. This result indicates that the large particles were more effectively removed from the indoor air of station than small ones. This PM number concentration may be also varied with the positions in subway station such as station geometry and column and stairwell locations, resulting in differences in pollutant transport and dispersion. The dissimilarity of PM number concentration among different positions in subway station, which is probably ori- 


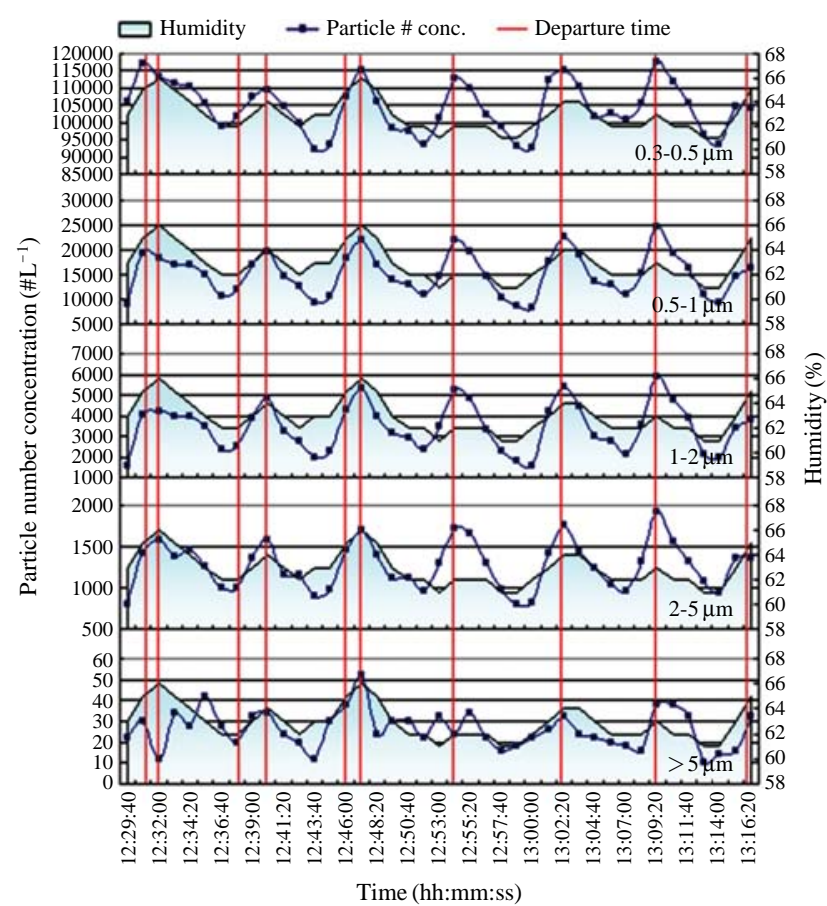

(a)

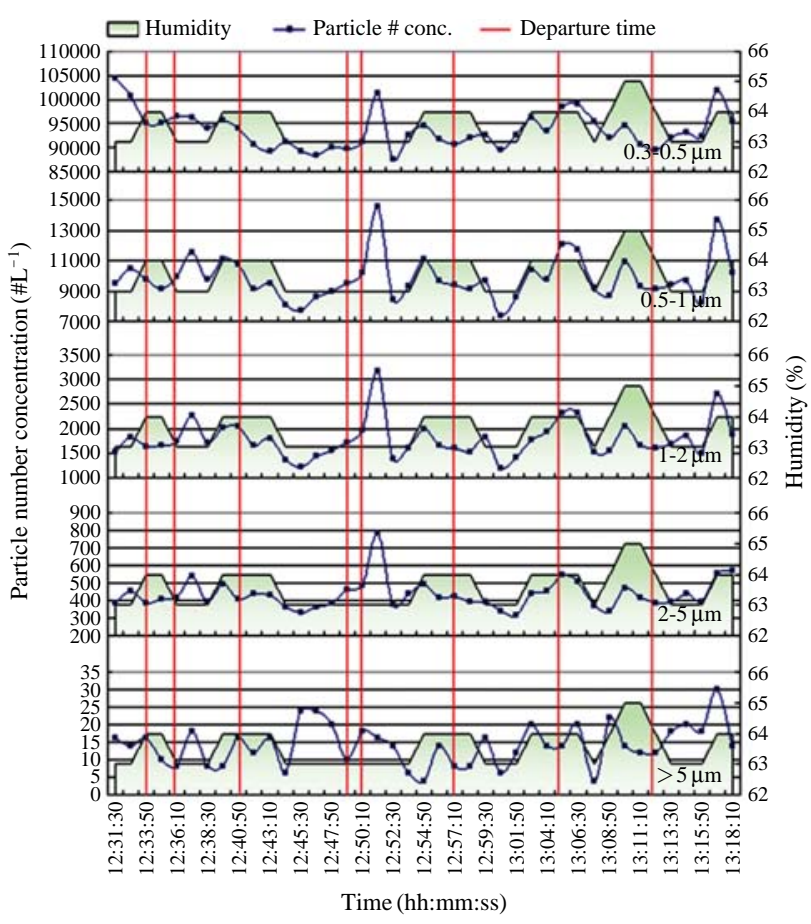

(b)

Fig. 3. Time series fluctuations of size-classified particle number concentration and humidity while trains run at a constant number at $\mathrm{B} 3 \mathrm{~F}(\mathrm{a})$ and $\mathrm{B} 2 \mathrm{~F}(\mathrm{~b})$.

ginated by turbulent airflow properties generated from train motion, can be expected. Richmond-Bryant and Wittig (2009) simulated a train movement by pushing air through the tunnel intake and past the model car. According to their model experiment, the regions of high concentrations and air velocities were observed at the leading edge of train and along the sides of train at subway platform.

The airborne PM number concentration in indoor of subway station can be generally decided by several particle types such as the particles newly generated by track wear, the resuspended particles by train motion, the particles carried by passengers, the particles influxed from station entrances, the particles infiltrated from outdoors, etc. These PM having various sources are cyclically circulated (generated and inflowing-suspending-falling down-resuspending) in a complex subway environment. Of course, some fractions of PM in indoor of subway station can be discharged by a series of fans and air shafts.

The particles settled down on the surface of platform will resuspend when a wind blows. The footstep of passengers compresses surface of platform and creates high velocity air flow. This air flow can resuspend the particles deposited on the surface of platform because flow velocity is enough to overcome adhesion between particle and surface.

The continuous data for the level of humidity illustrated in Fig. 3 shows the maximum during a train staying. This might be caused the effluence of humid atmosphere from the indoor of train. Humid air has a higher viscosity in the airway, therefore the air of high humidity blown out from the indoor of train can affect PM settling. Added to this, the humidity of subway environment can also vary the susceptibility of commuters to pollutant exposure because the inhaled particle deposition primary depends on particle size, particulate number density, breathing rate, aerodynamics of lung, and relative humidity (Saini et al., 2002).

In Fig. 4, the size-classified particle number concentrations among several different indoor and outdoor sites are compared. Relatively high number concentrations appeared in the PM larger than $1 \mu \mathrm{m}$ on $\mathrm{B} 3 \mathrm{~F}$. Interestingly, the particle $(>1 \mu \mathrm{m})$ counting data shows that particle numbers were 2 to 3 times higher in the air of subway platform as compared to aboveground outdoor site. This suggests that the operation of train in the semi-closed underground space of subway is very effective at generating PM in this size and that much of the produced PM is probably accumulating in the indoor space of station. On the other hand, the fine mode $\operatorname{PM}(<1 \mu \mathrm{m})$ countered at the outdoor air of sub- 

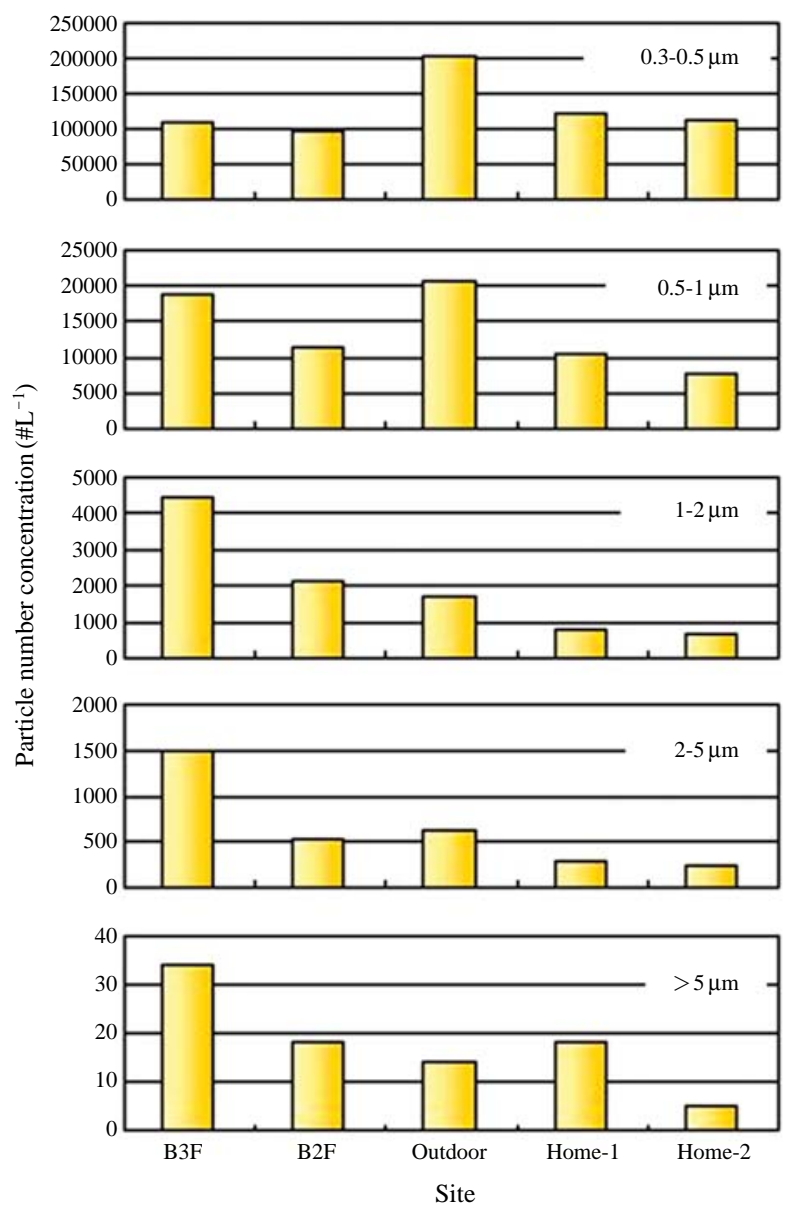

Fig. 4. Comparison of size-classified particle number concentration among several different indoor and outdoor sites.

way station in which submicron diesel PM can be easily distributed marks the highest level of number concentration. This ultrafine particle level at the outdoor environment can adversely affect to the underground space of subway because particles can enter the underground stations via the subway tunnels and entrance. In the PM ranged from $0.5 \mu \mathrm{m}$ to $5 \mu \mathrm{m}$, the lowest concentrations occurred at home. The relative concentrations of particle number countered on $\mathrm{B} 2 \mathrm{~F}$ were lower than those of B3F through whole size fraction.

To estimate the mass concentrations of size-segregated particles on $\mathrm{B} 3 \mathrm{~F}$ and $\mathrm{B} 2 \mathrm{~F}$, we conducted the gravimetric analysis for the PM captured on the filters of MCI sampler. The result of intercomparision is displayed in Fig. 5. PM2.5 accounts for 58.2\% and 38.2\% of TSP (i.e., the sum of PM2.5, PM10-2.5, and PM larger than $10 \mu \mathrm{m}$ ) on B3F and B2F respectively. As discussed above, this dissimilarity between two different depths of platform might be driven from the different situations of train travelling, air circulation, passen-

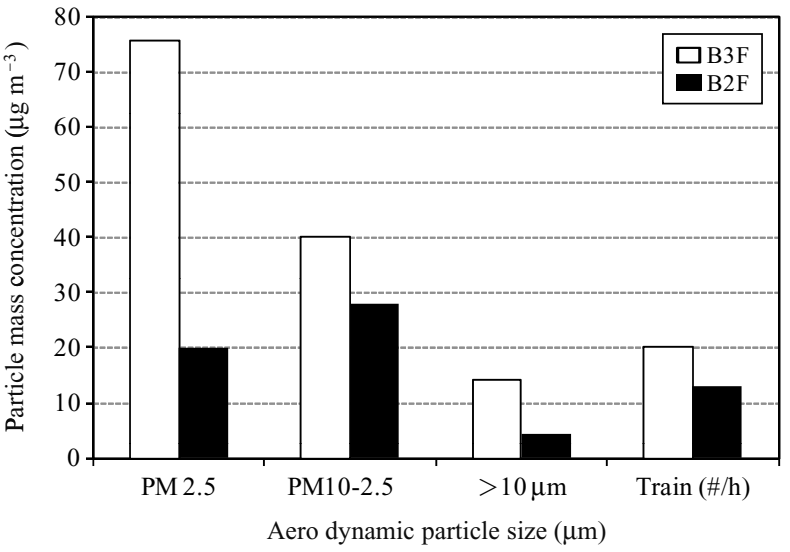

Fig. 5. Mass concentration of size-resolved particles with the number of train running at $\mathrm{B} 3 \mathrm{~F}$ and $\mathrm{B} 2 \mathrm{~F}$.

ger amount, etc. In the case of the average level of B3F and B2F, PM2.5 $\left(47.8 \mu \mathrm{g} \mathrm{m}^{-3}\right)$ was about a half of TSP $\left(91.1 \mu \mathrm{g} \mathrm{m}^{-3}\right)$, whereas the average giant particle larger than $10 \mu \mathrm{m}$ account small portion of TSP $(10.9 \%$ on $\mathrm{B} 3 \mathrm{~F}$ and $8.2 \%$ on B2F). Meanwhile, the levels of PM $10\left(115.8 \mu \mathrm{g} \mathrm{m}^{-3}\right.$ on B3F, $47.9 \mu \mathrm{g} \mathrm{m}^{-3}$ on B2F) did not exceed the SPM $(\leq 10 \mu \mathrm{m})$ level $\left(150 \mu \mathrm{g} \mathrm{m}^{-3}\right)$ recommended by the Law for Maintenance of Sanitation in Buildings in Japan. However, the PM10 concentration on B3F was nearly three to four times higher than those of urban outdoor ambient reported by Hamamurar et al. (2000).

\section{2 Elemental Concentration of Semi-bulk PM}

For the purpose of clear differentiation of the chemical property of fine PM from that of large PM, in this study, one of the particle clusters formed below the 1st stage nozzle and a portion of back-up filter of MCI sampler on both B3F and B2F were selected and irradiated by PIXE analytical beam. Fig. 6 shows the mass concentrations of elements that exceeded the analytical detection limit and the levels in blank filter. The elements observed at high concentrations were $\mathrm{Fe}, \mathrm{Si}$, $\mathrm{Ca}, \mathrm{S}$, and $\mathrm{Na}$. The major elements of which concentrations were relatively higher on $\mathrm{B} 3 \mathrm{~F}$ than $\mathrm{B} 2 \mathrm{~F}$ were $\mathrm{Fe}$ (4.4 times), $\mathrm{Ca}$ (17.3 times), and $\mathrm{Si}$ (46.4 times). Their PM2.5-to- > PM10 ratios on B3F are 19.2, 13.5, and 18.2, respectively. Fe might be origin from the steel dusts which were produced as numerous train wheels roll through the subway tunnels. Several earlier studies (Kim and Ro, 2010; Lorenzo et al., 2006; Okinaga et al., 2000) indicated that $\mathrm{Fe}$ was a major source of pollution in one of the world's most extensive commuter rail systems. And Mori et al. (2007) reported that the thermal metamorphism of train wheels gene- 


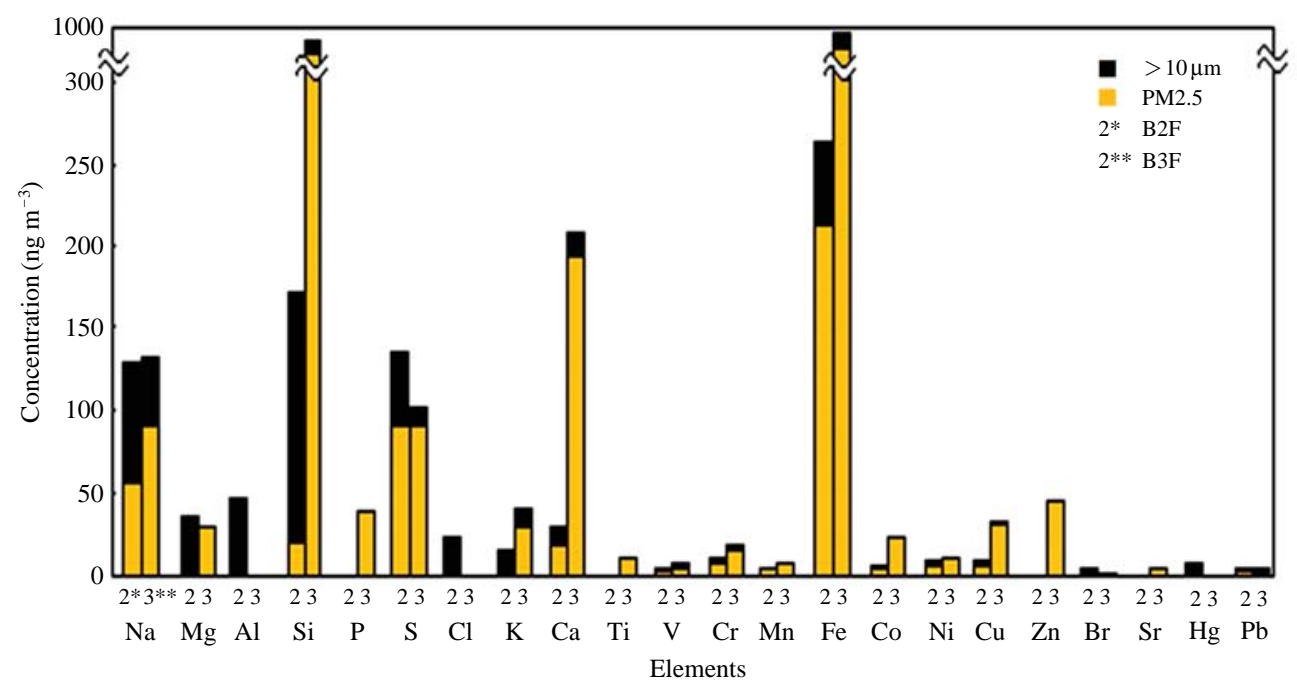

Fig. 6. Elemental concentration of size-resolved semi-bulk PM at B3F and B2F.

rating toxic particles in subway stations was a possibility. Subway workers and people who use subway regularly may be at the high risk of airborne particulate $\mathrm{Fe}$ exposure.

Feldspar $\left(\mathrm{KAlSi}_{3} \mathrm{O}_{8}-\mathrm{NaAlSi}_{3} \mathrm{O}_{8}-\mathrm{CaAl}_{2} \mathrm{Si}_{2} \mathrm{O}_{8}\right)$ and granite $\left(\mathrm{SiO}_{2}, \mathrm{Al}_{2} \mathrm{O}_{3}, \mathrm{~K}_{2} \mathrm{O}, \mathrm{Na}_{2} \mathrm{O}, \mathrm{CaO}, \mathrm{FeO}\right.$, etc.) which are the group of rock-forming tectosilicate minerals were found as the component of the gravel underneath the railway tracks. In Japan, feldspar and granite are found as common gravel underneath the railway tracks. Lorenzo et al. (2006) stated that very fine PM could be generated by a high-temperature process during breaking because this temperature was high enough to melt feldspar particles. Hence, the high concentrations of $\mathrm{Si}, \mathrm{Ca}$, and $\mathrm{Na}$ in $\mathrm{PM} 2.5$ were presumably produced by the melting of gravel granules during breaking.

Although, the quantity were very small, $\mathrm{Cr}(11.9 \mathrm{ng}$ $\mathrm{m}^{-3}$ on B3F, $2.4 \mathrm{ng} \mathrm{m}^{-3}$ on B2F), Mn (3.4 $\mathrm{ng} \mathrm{m}^{-3}$ on B3F, $0.9 \mathrm{ng} \mathrm{m}^{-3}$ on B2F), and $\mathrm{Pb}\left(0.6 \mathrm{ng} \mathrm{m}^{-3}\right.$ on B3F, $1.6 \mathrm{ng} \mathrm{m}^{-3}$ on $\mathrm{B} 2 \mathrm{~F}$ ) were detected from PM2.5. However, there is increasing interest in whether there are health effects from long-term exposure to low-levels of pollutants such as chromium and manganese, as well as from inhaling airborne transition metals (Chillrud et al., 2005).

\section{3 Elemental Composition and Source Profile of Individual Particles}

Fig. 7 illustrates an example of 2D-elemental distribution on individual particles collected on the backup filter of MCI installed on B3F. The whole scan area of micro-beam was $0.1 \mathrm{~mm} \times 0.1 \mathrm{~mm}$. When a microbeam is scanned on a sample surface, the micro-PIXE method provides the spatial distribution of the ele- ments in and/or a particle. In line with general expectation, the particles of this scan area consist almost entirely of Fe. Also, minor amounts of other elements were occasionally detected. The Fe enrich particles were chemically mixed with several minor compositions such as mineral and heavy metal elements. The reason of this chemical mixing state might be that smaller particles sat on top of - or close to - the iron particles, namely the external chemical mixing. The existence of the original particles containing multi elemental components (i.e., internal chemical mixing) cannot also be rejected. The elemental map of individual particles drawn by micro-PIXE analysis can be applied to their fingerprint for tracing their origin. The elemental mask resynthesized from every elemental map was drawn at the bottom left of Fig. 7. The elemental compositions of these resynthesized individual 13 particles are also listed in the bottom right corner of Fig. 7.

The classification of individual particles, which relies on both physical appearance and chemical property, should be a reasonable way for the finger printing of particles. On the basis of characteristic elements and the morphology of particles, total 150 individual particles irradiated by micro-PIXE were classified and their expected sources were presumed in Table 1. Most of the irons containing particles have two kinds of appearance in shape namely, small spherical and large irregular shapes. The relatively large irregular shape of Ferich particles $(\mathrm{Fe}>\mathrm{Si}, \mathrm{Ca}$, and $\mathrm{Al})$ looked like splinters and they were most likely generated by the physical friction and mechanical abrasion (or collision) among train body, wheel, and rail. Meanwhile, the fine round shape particles containing Fe was also frequently found. 

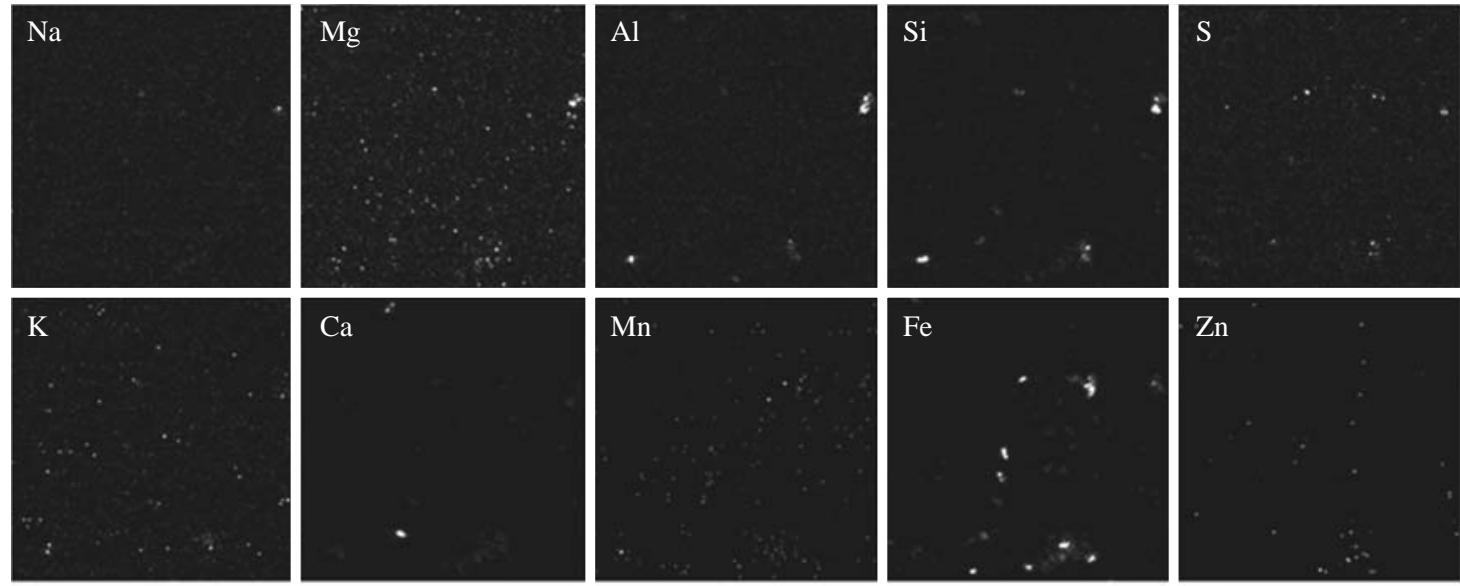

Zero
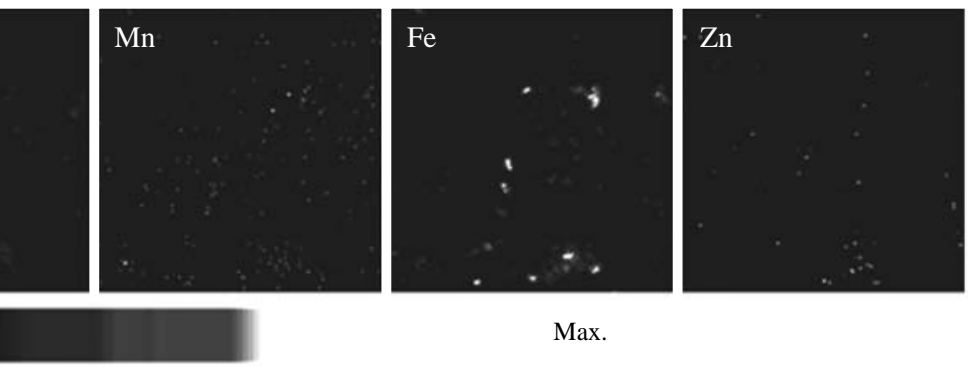

Max

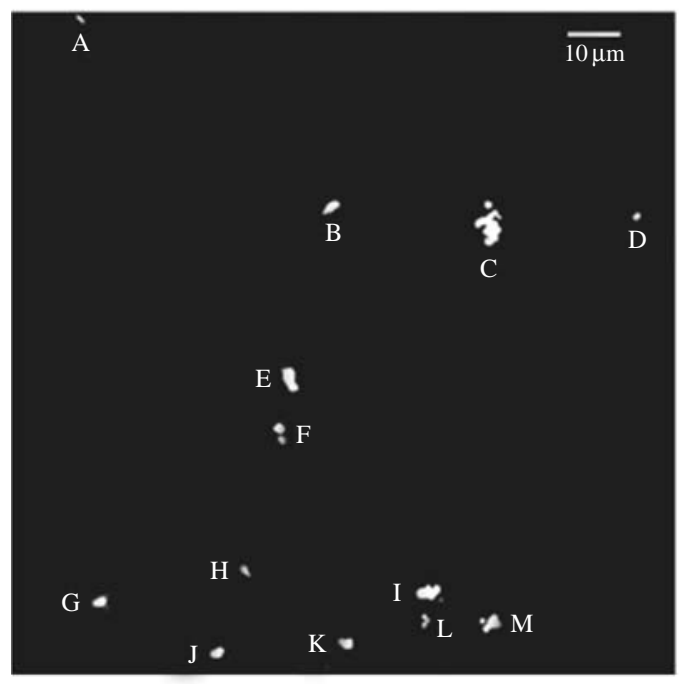

$\mathrm{A}: \mathrm{Ca}>\mathrm{Si}>\mathrm{Al}$

B: $\mathrm{Fe}>\mathrm{Si}>\mathrm{S}>\mathrm{Ca}>\mathrm{Mg}$

C: $\mathrm{Fe}>\mathrm{Ca}$

D: $\mathrm{Al}>\mathrm{Si}>\mathrm{Fe}>\mathrm{Ca}>\mathrm{Mg}>\mathrm{Na}>\mathrm{S}$

$\mathrm{E}: \mathrm{Fe}>\mathrm{Ca}$

$\mathrm{F}: \mathrm{Fe}$

$\mathrm{G}: \mathrm{Si}>\mathrm{Al}>\mathrm{Ca}>\mathrm{K}$

$\mathrm{H}: \mathrm{Ca}>\mathrm{Fe}>\mathrm{Si}>\mathrm{S}$

I: $\mathrm{Fe}>\mathrm{Si}>\mathrm{Al}>\mathrm{Ca}>\mathrm{S}>\mathrm{K}>\mathrm{Zn}$

J: $\mathrm{Fe}$

$\mathrm{K}: \mathrm{Fe}>\mathrm{Al}>\mathrm{Si}$

$\mathrm{L}: \mathrm{Fe}>\mathrm{Ca}$

$\mathrm{M}: \mathrm{Fe}>\mathrm{Si}>\mathrm{Ca}$

Fig. 7. 2D-elemental distribution on individual particles (PM2.5) collected at B3F (Scan: $X=0.1, Y=0.1 \mu \mathrm{m})$.

Table 1. Classifying and source profiling of the individual particles by the elemental maps dawn by micro-PIXE (Scan: $X=0.1$, $\mathrm{Y}=0.1 \mathrm{~mm})$.

\begin{tabular}{|c|c|c|c|c|}
\hline Category & Characteristic $\mathrm{Z}$ & Morphology & Size & Expected source \\
\hline Class 1 & $\mathrm{Fe}>\mathrm{Si}, \mathrm{Ca}, \mathrm{Al}$ & Irregular & Large & Train/Rail (mechanical abrasion) \\
\hline Class 2 & $\mathrm{Fe}$ & Spherical & Small & Train-Rail (melting/sparkling ) \\
\hline Class 3 & $\mathrm{Si}>\mathrm{Al}, \mathrm{Fe}, \mathrm{Ca}$ & Irregular/Spherical & Large/Small & Ballast/Coated abrasive \\
\hline Class 4 & $\mathrm{Ca}>\mathrm{Si}, \mathrm{Al}, \mathrm{Fe}$ & Irregular & Large & Gravel/Cement beneath track \\
\hline
\end{tabular}

This morphology indicates that the particles divided into Type 2 were probably generated by a high-temperature process during train wheel and rail sparkling. Fe enrichment particles grouped in Type 1 and 2 account $72.7 \%$ of total analyzed particles.

Both large irregular and small round shapes of particles classified in Type 3 were presumably originated from the ballast and the abrasive. In order to promote the adhesive power during train's departure and stopping, the abrasive $\left(\mathrm{SiO}_{2}, \mathrm{TiO}_{2}, \mathrm{Al}_{2} \mathrm{O}_{3}, \mathrm{Fe}_{2} \mathrm{O}_{3}, \mathrm{FeO}, \mathrm{MnO}\right.$, $\mathrm{MgO}$, etc.) were coated on train wheel surface (The society of Kyoto natural whetstone, 2006). Due to the high-temperature generated between train wheel and rail during breaking, not only metal (train wheel and rail) and ballast (feldspar and granite) also abrasive can be melted, then small spherical shapes particles can be 
generated. The $\mathrm{Ca}>$ Si-rich particles with large irregular shape classified in Type 4 were probable traced back to the cement used as rail sleeper and track ballast. Continuous soil-cement walls installed underground for the purposes of excavation support, ground water control and containment of contaminated soil were also possible source of Type 4 particles.

However, our source profile method for fine individual particles still has a limitation in conclusive particle classification because of the micro-PIXE's resolution ability of elemental maps for the minor elements contained in many other sources existing in subway environments (break pad, lining, etc.) and outdoor sources (combustions, soils, secondary emissions, etc.).

\section{CONCLUSIONS}

There has been increasing concern to the air quality in the underground spaces of subway because the indoor air in this semi-sealed off space have a major source of aerosol by the movement of train, the passenger's coming in and out, and restricted ventilation system. To make matters worse, many people within the worldwide metropolitan areas are using subway transportation and spend considerable time in the underground subway environment on a daily basis. Under this situation, in the current study, an attempt was made to understand the physicochemical properties of indoor particulate matters collected on subway platforms. Although, the levels of PM10 on B3F did not exceed the SPM level recommended by the Law for Maintenance of Sanitation in Buildings in Japan, this PM10 concentration was nearly three to four times higher than those of urban outdoor ambient. Subway $\mathrm{PM}$ was dominated by $\mathrm{Fe}, \mathrm{Si}$, and $\mathrm{Ca}$ and contains $\mathrm{Mn}, \mathrm{Cr}$, and $\mathrm{Pb}$ as minor components. These unique chemical compositions of PM were shown in both semi-bulk and single particles and suggest that PM emission sources in the underground subway were very different from those in outdoor ambient. Due to the analytical limit of micro-PIXE, unfortunately, the particle composited by carbonaceous and secondary aerosols such as nitrates and sulfates could not estimated in the current study. Moreover, as compared to bulk sample analysis, in the case of single particle analysis, only a small portion of the particle deposition area was the target of analysis. Although further study would be needed to estimate more thoroughly the PM pollution in underground environment of subway because the numerical limitation of particles that individually analyzed in the present study is apprehensive, the results of current study indicate that the air quality, especially the ultrafine particle on the platforms show- ing the elevated level during rush hour, is the serious concern of daily commuters, particularly the sensitive subpopulation with respiratory diseases. In order to keep the air of underground subway space breathable, namely environmentally friendly subways, one should improve the subway structures, e.g., station entrances that are naturally circulate the air, fans and air shafts that effectually circulate fresh air, the platform screen door that efficiently isolate station and tunnel, the PM precipitator, etc.

\section{ACKNOWLEDGEMENT}

This work was funded in part by the Ministry of Education, Culture, Sports, Science and Technology (Grantin-Aid for Scientific Research B, No. 23360419). The author expresses a sincere thank to all staffs of the N$\mathrm{K}$ subway station for their experimental cooperation and support.

\section{REFERENCES}

Chillrud, S.N., Grass, D., Ross, J.M., Coulibaly, D., Slavkovich, V., Epstein, D., Sax, S.N., Pederson, D., Johnson, D., Spengler, J.D., Kinney, P.L., Simpson, H.J., Brandt-Rauf, P. (2005) Steel dust in the New York City subway system as a source of manganese, chromium, and iron exposures for transit workers. Journal of Urban Health: Bulletin of the New York Academy of Medicine 82, 33-42.

Dockery, D.W., Pope, C.A., Xu, X., Spengler, J.D., Ware, J.H., Fay, M.E., Ferris, B.G., Speizer, F.E. (1993) An association between air pollution and mortality in six U.S. cities. The New England Journal of Medicine 329, 1753-1759.

Fujikawa, K., Yamamoto, S., Tagami, S., Chikara, H., Oishi, O., Iwamoto, S. (2008) The behavior of carbon compounds (EC,OC) in aerosols. The annual report of Fukuoka Institute of Health and Environmental Sciences 35, 93-97. (in Japanese)

Furuya, K., Kudo, Y., Okinaga, K., Yamuki, M., Takahashi, S., Araki, Y., Hisamatsu, Y. (2001) Seasonal variation and their characterization of suspended particulate matter in the air of subway stations. Journal of Trace and Microprobe Techniques 19, 469-485.

Gulyas, H., Gercken, G. (1988) Cytotoxicity to alveolar macrophages of airborne particles and waste incinerator fly-ash fractions. Environmental Pollution 51, 1-18.

Hamamura, K., Iwamoto, S., Utsunomiya, A., Ohishi, O., Shimohara, T., Hisatomi, K. (2000) Influence of vehicle emissions on air pollutants near heavy traffic roads in Fukuoka Prefecture. The research report of Fukuoka Institute of Health and Environmental Science 27, 4953. (in Japanese) 
International Atomic Energy Agency (IAEA)-TECDOC1190 (2000) Instrumentation for PIXE and RBS, pp. 178.

Ishii, K., Sugimoto, A., Tanaka, A., Satoh, T., Matsuyama, S., Yamazaki, H., Akama, C., Amartivan, T., Endoh, H., Oishi, Y., Yuki, H., Suegara, S., Satoh, M., Kamiya, T., Sakai, T., Arakawa, K., Saidoh, M., Oikawa, S. (2001) Elemental analysis of cellular samples by in-air micro-PIXE. Nuclear Instruments and Methods in Physics Research B 181, 448-453.

Kim, H.K., Ro, C.U. (2010) Characterization of individual atmospheric aerosols using quantitative energy dispersive-electron probe X-ray microanalysis. Asian Journal of Atmospheric Environment 4, 115-140.

Lorenzo, R., Kaegi, R., Gehrig, R., Grobéty, B. (2006) Particle emissions of a railway line determined by detailed single particle analysis. Atmospheric Environment 40, 7831-7841.

Matsuyama, S., Ishii, K., Yamazaki, H., Sakamoto, R., Fujisawa, M., Amartaivan, T., Ohishi, Y., Rodriguez, M., Suzuki, A., Kamiya, T., Oikawa, M., Arakawa, K., Matsumoto, N. (2003) Preliminary results of microbeam at Tohoku University. Nuclear Instruments and Methods in Physics Research Section B 210, 59-64.

McDonnell, W.F., Nishino-Ishikawa, N., Petersen, F.F., Chen, L.H., Abbey, D.E. (2000) Relationships of mortality with the fine and coarse fractions of long-term ambient SPM concentrations in nonsmokers. Journal of Exposure Analysis and Environmental Epidemiology $10,427-436$.

Mori, T., Inudo, M., Takao, Y., Koga, M., Takemasa, T., Shinohara, R., Arizono, K. (2007) In vitro evaluation of atmospheric particulate matter and sedimentation particles using yeast bioassay system. Environmental Sciences 14, 203-210.

Okinaga, K., Takahashi, S., Tsugoshi, T., Kudo, Y., Furuya, K., Araki, Y. (2000) Characterization of suspended particulate matter in the air in subways and corresponding above-ground areas. Journal of Japan Society Atmo- spheric Environment 35-1, 12-20.

Ozao, S. (1977) Field study on airborne particulate concentration in subway. Kogai to Taisaku 13, 974-984. (In Japanese)

Pope, C.A., Bates, D.V., Raizenne, M.E. (1995) Health effects of particulate air pollution: Time for reassessment. Environmental Health Perspectives 103, 472-480.

Pope, C.A., Hill, R.W., Villegas, G.M. (1999) Particulate air pollution and daily mortality on Utah's Wasatch Front. Environmental Health Perspectives 107, 567573.

Richmond-Bryant, J., Wittig, A.E. (2009) Particle image velocimetry experiments of transport and dispersion of air pollutants in a model subway station. The 28th Annual Conference of American Association for Aerosol Research, October 26, Minnesota, US, 899.

Saini, D., Yurteri, C.U., Grable, N., Sims R.A., Mazumder, M.K. (2002) Effect of charge on the deposition of electrostatically charged inhalable aerosol in lung model. Journal of the Arkansas Academy of Science 56, 146-152.

Sera, K., Futatsugawa, S., Matsuda, K. (1999) Quantitative analysis of untreated bio-samples. Nuclear Instruments and Methods in Physics Research B 150, 226-233.

Son, Y.S., Kang, Y.H., Chung, S.G., Park, H.J., Kim, J.C. (2011) Efficiency evaluation of adsorbents for the removal of VOC and $\mathrm{NO}_{2}$ in an underground subway station. Asian Journal of Atmospheric Environment 5, 113-120.

The society of Kyoto natural whetstone (2006) The fascinating Kyoto natural whetstone Vol. 3, The society of Kyoto natural whetstone, pp. 1-90.

Yoshizawa, S. (1983) Pollution by airborne microbiological particles in subway stations. Journal of Antibacterial and Antifungal Agents 11, 137-149.

(Received 19 April 2011, revised 20 December 2011, accepted 20 December 2011) 